\title{
ADJECTIVES IN THE EXPRESSION OF EPISTEMIC MODALITY IN APPLIED LINGUISTICS RESEARCH ARTICLES
}

\author{
Attapol Khamkhien \\ Department of English, Faculty of Liberal Arts and Science, \\ Kasetsart University, Thailand \\ E-mail: faasapk@ku.ac.th
}

Received: 2021-11-10

Accepted: 2021-12-05

\begin{abstract}
Research in academic writing has shown that writers have a strong tendency to communicate their ideas interactively with readers. This study examines how professional writers use adjectives as part of interactional metadiscourse when writing research articles. A total of 255 research articles published in distinguished journals in the field of applied linguistics between 2015 and 2020 were systematically compiled and quantitatively and qualitatively analysed. The extent to which epistemic adjectives and typical phraseological patterns are used in research articles was investigated with the help of corpus linguistics methods, as was their epistemic strength indicated by writers. The interpersonal model of metadiscourse was used as the theoretical framework for the study. The findings suggest that the academic writing corpus, in essence, is interactionally oriented, while the use of adjectives as an epistemic modality reflects a methodical approach by article writers when presenting propositions and discussing their knowledge claims. This study provides a deeper understanding of these linguistic features to impact the reader. Pedagogically, the study can be useful for teaching academic writing to postgraduate students and help them and novice writers develop writing competency through epistemic devices, especially in research articles intended for publication.
\end{abstract}

Keywords: epistemic modality, adjectives, writing for publication, research articles

\section{Introduction}

Traditionally, academic writing has widely assumed that researchers should be objective and produce an unbiased writing style when reporting on studies. However, this conventional view of academic writing was challenged and discredited by a number of researchers (Harwood, 2005; Hyland, 2004, 2005, 2009; Flowerdew, 1999, 2008). Thus, scholars have become more interested in the ways in which writers convey meaning in academic discourse through metadiscourse elements as various approaches have been adopted in linguistics (e.g. Abdi, 2011; Del Saz-Rubio, 2011; Ghahremani \& Biria, 2017; Hyland, 2005, 2007; Jalilifar et al., 2018; Letsoela, 2014; Lin, 2005; Loi \& Lim, 2013; Molino, 2018).

The topic of how writers deploy metadiscourse in English academic texts has received much attention in recent decades (e.g. Hyland 2005; Hyland \& Tse, 2004; Harwood, 2005; Lee \& Deakin, 2016; Ho \& Li, 2018), and the definition of metadiscourse has been interpreted from different perspectives. According to Hyland (2005), metadiscourse can be 
used to persuade others by appealing to reason, credibility, character and emotion. Metadiscourse is also seen as a linguistic resource that writers can use to intrude themselves into the text, to interact with the reader (Crismore \& Farnsworth, 1990; Hyland, 2005) and to modify their propositions to produce coherent and persuasive texts (Hyland \& Tse, 2004). In the same vein, Vande Kopple (2012) defines metadiscourses as resources that help readers to "connect, organize, interpret, evaluate and develop attitudes towards the materials" ( $p$. 93).

Meanwhile, research on writing in English for Academic Purposes (EAP) has shifted from the production of academic texts by students to writing problems in professional scholarly communication. This research interest has highlighted the importance of linguistic knowledge and rhetorical patterns in published texts, mainly research articles in journals (e.g. Kanoksilapatham, 2015, Flowerdew \& Li, 2009). Meanwhile, much of the research on research articles (e.g. Babaii, Atai, Mohammadi, 2015; Chovanec, 2012; Salager-Meyer, 2008) has asserted that non-native academics need to use choice and linguistic features to meet the expectations of the respective discourse community, which are often based on Anglo-American norms (Chen, 2010; Chovanec, 2012; Lin \& Evans, 2012; Martinéz, 2005) in order to be accepted for journal publication. According to Hyland (2003), the linguistic knowledge base of $L 2$ writers differs from that of native English speakers and professional writers. While most native speakers have lexical items and "an intuitive ability to deal with the grammar of the language when they begin to write, L1 and L2 writers often carry the burden of learning to write and learning English at the same time" (p. 34). For this reason, many newcomers to the L2 context and EFL face challenges and difficulties when it comes to publishing their research articles in distinguished academic journals.

In recent decades, a considerable amount of research has been carried out on the use of epistemic modality as a rhetorical feature for presenting claims and arguments in academic research papers written by native English speakers (Ardizzone \& Pennisi, 2012; Chovanec, 2012; Giannoni, 2008; Hyland 2005, 2007, 2010, 2012; Orta, 2010; Thompson, 2001; Vold, 2006). In general, findings show that writers whose first language is not English tend to adopt a normative scientific writing style to share knowledge and gain international recognition (e.g. Flowerdew, 2008; Ngula, 2015, 2017; Vandenhoek, 2018). Likewise, the frequency of linguistic features expressing interactional and interpersonal metadiscourse in academic writing can also vary considerably from one discipline to another due to their differences and cultural backgrounds (Gillaerts \& Van de Velde, 2010; Hyland, 2005; Hong \& Cao, 2014; Salager-Meyer et al. 2003; Varttala, 2001). Some studies (e.g. Fintel \& Gillies, 2007; Ngula, 2015, 2017) have attempted to identify the expressions of epistemic modality used in scientific English and proposed a classification that highlights the necessity and/or possibility of an underlying claim in relation to a body of evidence.

Despite the growing body of research concerning metadiscourse in academia, there is very little empirical research that thoroughly and robustly examines the use of epistemic adjectives expressing modality in science articles. Moreover, research studies have shown that modality expressions are used for different purposes depending on the writer's intention. Given the importance of linguistic devices used in academic texts, this study focuses on the modality and epistemic adjectives in a particular genre. Its aim is to investigate the use of epistemic adjectives in research articles taken from the field of applied linguistics to achieve persuasion, acceptance and ratification by potential readers. The overall aim is to examine common epistemic adjectives and their application and distribution of markers or their phraseological patterns used to reinforce the expressed modal meaning 
(Huddleston \& Pullum, 2002) in research articles. The present study specifically aims to find answers to the following questions:

I. What are the epistemic adjectives used in research articles in applied linguistics?

II. What are the typical phraseological patterns of core epistemic adjectives found in these research articles?

III. What are the degrees of epistemic adjectives (weak, medium or strong) in the discipline of applied linguistics?

\section{Literature Review}

\subsection{Interactions in academic writing and taxonomy of metadiscoursal features}

According to Hyland (2010), academic texts are no longer "as completely author evacuated as we had once supposed. Instead, they are actually comprised of careful evaluations and interactions" (p. 116). He claims that research articles are places where authors not only reveal their new perspectives but also seek to build and maintain relationships with their credible readers. In academic discourse, Hyland (2010) has focused on the concept of interpersonality, which refers to the ways in which the writer and reader(s) establish, maintain and signal their relationships.

Researchers have discussed interactional or interpersonal linguistic resources in academic texts under broad terms such as metadiscourse (Hyland \& Tse, 2004; Hyland, 2005; 2013), stance (Biber, 2004; 2006), evaluation (Hunston, 1994; Hunston \& Thompson, 2000, 2006) and appraisal (Martin, 2000; Martin \& White, 2005). There seems to be a great deal of overlap in the interpersonal linguistic resources covered by these terms. However, most of them include categories that fall within the domain of epistemic modality. In terms of metadiscourse, Hyland (2013) discusses that metadiscourse refers to the self-reflective expressions used to negotiate interactional meanings in a text, assist the writer to express a viewpoint and engage with readers as members of a particular community. This includes the personalities, attitudes and assumptions of those who are communicating (Hyland, 2005). Based on the assumption that writing is a two-way process between the writer and the reader, metadiscourse features are the elements through which the writer projects and represents him/herself in the course of writing and shows his/her attitude towards the content and readership of the message (Hyland \& Tse, 2004; Hyland, 2013).

Based on the above principles, Hyland (2005) developed his interpersonal model or taxonomy of metadiscourse, which consists of two main categories - interactive and interactional. The function of interactive metadiscourse is to guide the reader through the text, while the function of interactional metadiscourse is to engage the reader in the text. Each category has its own sub-category as follows:

\begin{tabular}{|c|c|c|}
\hline Categories & Functions & Examples \\
\hline \multicolumn{3}{|c|}{ Interactive metadiscourse } \\
\hline Transitions & $\begin{array}{l}\text { Express relations between main } \\
\text { clauses. }\end{array}$ & In addition, but, thus, and \\
\hline $\begin{array}{l}\text { Frame } \\
\text { markers }\end{array}$ & $\begin{array}{l}\text { Refer to discourse acts, sequences and } \\
\text { stages. }\end{array}$ & $\begin{array}{l}\text { Finally, the aim is, in conclusion, } \\
\text { the purpose is }\end{array}$ \\
\hline $\begin{array}{l}\text { Endophoric } \\
\text { markers }\end{array}$ & $\begin{array}{l}\text { Refer to information in other parts of } \\
\text { the text. }\end{array}$ & $\begin{array}{l}\text { As mentioned above, in the next } \\
\text { paragraph }\end{array}$ \\
\hline Evidentials & Refer to information from other texts. & $X X$ argued that, according to $Y Y$ \\
\hline $\begin{array}{l}\text { Code } \\
\text { glosses }\end{array}$ & Elaborate propositional meanings. & $\begin{array}{l}\text { That is, for example, in other } \\
\text { words, namely, such as, e.g. }\end{array}$ \\
\hline
\end{tabular}




\begin{tabular}{|l|l|l|}
\hline Interactional & metadiscourse \\
\hline Hedges & $\begin{array}{l}\text { Withhold commitment and open } \\
\text { dialogue. }\end{array}$ & $\begin{array}{l}\text { May, might, perhaps, probably, I } \\
\text { guess }\end{array}$ \\
\hline Boosters & $\begin{array}{l}\text { Emphasise certainty or close } \\
\text { dialogue. }\end{array}$ & Certainly, in fact, it is clear that \\
\hline $\begin{array}{l}\text { Attitude } \\
\text { markers }\end{array}$ & $\begin{array}{l}\text { Express writer's attitude to } \\
\text { propositions. }\end{array}$ & $\begin{array}{l}\text { (un)fortunately, (un)deniably, } \\
\text { surprisingly }\end{array}$ \\
\hline $\begin{array}{l}\text { Self- } \\
\text { mentions }\end{array}$ & Refer to the writer explicitly. & I, we (exclusive), our \\
\hline $\begin{array}{l}\text { Engagement } \\
\text { markers }\end{array}$ & $\begin{array}{l}\text { Build a relationship with readers } \\
\text { explicitly. }\end{array}$ & You, we (inclusive), note... \\
\hline
\end{tabular}

Table 1. An Interpersonal Model of Metadiscourse Features (Hyland, 2005)

The concept of interactional metadiscourse is indeed an uncommon phenomenon in academic texts. Previous research has shown that interactive metadiscourse is used more frequently than interactional metadiscourse in various types of academic texts written by advanced and professional writers. For example, in argumentative essays written by university students (Lee \& Deakin, 2016; Ho \& Li, 2018), in master's or doctoral theses written by postgraduate students (Hyland, 2004) and in research articles written by professional writers (Mu, Zhang, Ehrich \& Hong, 2015). These studies demonstrate some degree of deviation from the prevailing discursive practise of academic writing in terms of different preferences of the two main categories of metadiscourse. They also assume that metadiscourse serves only to help the writer organise a text and be persuasive through appeals to rationality, credibility, character and emotion (Hyland, 2005).

\subsection{Epistemic modality markers and epistemic adjectives in academic writing}

According to Halliday (1994), epistemic modality is part of the interpersonal aspect of the three functional components of human language (ideational, interpersonal and textual), which in Systemic Functional Linguistics (SFL) are called "metafunctions". Flowerdew (1998) points out that epistemic modality is a sub-type of linguistic modality that involves knowledge, belief or confidence in a proposition. Epistemic modality refers to the reliability of the information conveyed, and epistemic modality markers are linguistic expressions that qualify the true value of the content of a statement. The evidence of epistemic modality available to the writer determines the degree of confidence and force supporting an assertion, statement or proposition. The linguistic expressions used to represent epistemic modality indicate varying degrees of commitment, with one end expressing doubt/doubtfulness and the other end expressing certainty/confidence on the continuum of epistemic modality (McEnery \& Kifle, 2002; Vold, 2006).

The fact that there are markers of epistemic modality in academic texts is positive evidence of the pragmatic aspects of such discourse (Hyland, 2013). More importantly, the writers' ability to appropriately manage the use of such devices in a text would reinforce the pragmatic aspect of their discourse, which may also reflect their high mastery of pragmatic writing skills. Consequently, this ability can also be indicative of the writers' overall linguistic competence (Chen, 2010), as it contributes to a more successful interaction with the content and the reader (Hyland, 2000, 2010, 2013).

As for the linguistic devices and resources used to express epistemic modality, the modal verbs (e.g. may, would, could, must) seem to be the prototypical and best known for 
this purpose. However, in addition to modal verbs, there are other useful lexical items that express epistemic modality. These include adjectives such as possible, probable, likely; adverbs such as perhaps, maybe, possibly; lexical verbs such as seem, appear, suppose; and nouns such as hope, possibility, assumption (Brogaard \& Gatzia, 2017; Holmes, 1988; Hoye, 1997). Rizomilioti (2006) discussed that epistemic modality markers can be represented through various linguistic forms and types including epistemic modal auxiliaries (might, would), epistemic lexical verbs (seem, suppose), epistemic adverbs (possibly, perhaps), epistemic adjectives (likely, probable) and epistemic nouns (claim, view). Similarly, Kranich and Gast (2012: 4) proposed four major syntactic types of epistemic modal markers in English, including modal auxiliaries (may, might, can, could, must), lexical modal verbs (seem, appear), modal adjectives or adverbs (likely, probably, perhaps), and modal periphrases (I would wager that ..., I doubt it ..., etc.). Therefore, it can be said that whatever terms have been proposed and used to explore such relations in discourses, these linguistic resources are employed to highlight and express more or less asserted knowledge and the representation of stance in academic text (Aull \& Lancaster, 2014).

One of the semantic categories was identified by Conrad and Biber (2000) who advocated that epistemic stance refers to the degree of certainty or reliability of a writer's proposition. However, the most interesting and influential taxonomy of epistemic stances was posited by Biber (2006). His taxonomy includes syntactic patterns that often occur in conjunction with epistemic modality and thus can lead to different meanings or perhaps pragmatic meanings. Biber's (2006) taxonomy of epistemic stance devices is presented in Table 2.

\begin{tabular}{|l|l|}
\hline Epistemic devices & Examples \\
\hline Adjective + that-clause & $\begin{array}{l}\text { It is also clear [that their cordiality and mutual respect was } \\
\text { enhanced rather than hampered by the geographical distance } \\
\text { between them]. }\end{array}$ \\
\hline Adjective + to-clause & $\begin{array}{l}\text { It is still scarcely possible [to distinguish between an identity, } \\
\text { securing core of tradition and a periphery open to revision]. }\end{array}$ \\
\hline Adverb & $\begin{array}{l}\text { But, what I really have to do though is to keep the total time } \\
\text { frame for each person, almost exact, to fifteen minutes. }\end{array}$ \\
\hline Noun + that-clause & $\begin{array}{l}\text { I started out with the assumption [that consciousness is } \\
\text { complete with the ontological proof]. }\end{array}$ \\
\hline Verb + that-clause & $\begin{array}{l}\text { We recognize [that it's a real error [unclear words] because he } \\
\text { pursues the ideal out of this world]. }\end{array}$ \\
\hline Verb + to-clause & $\begin{array}{l}\text { Many deep ecologists of today seem [to define human beings as } \\
\text { an alien presence on the earth]. }\end{array}$ \\
\hline
\end{tabular}

Table 2. Epistemic stance devices (Adapted from Biber, 2006: 105-113)

Since linguistic features or interpersonal rhetorical features play an important role in academic writing, scholars and researchers of composition theory have been interested in how writers use these interactional features to achieve persuasion, acceptance and ratification by readers. A number of studies investigated the use of metadiscourse markers in academic texts in terms of different variables such as genres, disciplines and languages. Özdemir and Longo (2014) used Hyland's taxonomy to compare the use of metadiscourse in MA thesis abstracts written by Turkish and US doctoral students in English. The investigation revealed some cultural differences in the amount and type of metadiscourse. In her dissertation, Çapar (2014) examined the use of interactional metadiscourse devices in 
academic research articles written by Turkish and American writers in a corpus of 150 research articles in the field of foreign language teaching and found that American academic writers used interactional metadiscourse markers more frequently than their Turkish counterparts. It is also worth noting that Turkish authors used more interactional metadiscourse markers when writing in English than in Turkish. Some studies have highlighted the importance of cultural differences as well as disciplines. In his comparative study of metadiscourse markers in two corpora that included 36 Persian and 36 English research papers, Abdi (2009) found that Persian writers express a distinct cultural identity when using interactional metadiscourse markers. Similarly, Blagojevic (2004) attempted to examine the use of metadiscourse markers in research articles written by English and Norwegian scholars in three different fields. He focused on the habitual cultural rhetoric of academic writers and discovered that psychology writers used more standard forms in their writing, whereas philosophy writers organised their work in a more diverse manner.

In addition, previous studies (e.g. Al-Shunnag, 2014; Biber et al., 1999; 2006; He \& Wang, 2012, Ngula, 2015; 2017, Orta, 2010, Siddique et al., 2019, Tenula et al., 2015) have used the lexico-grammatical framework of stance (Biber et al., 1999; 2006) to explore how writers from different backgrounds and disciplines use grammatical and lexical devices. Meanwhile, researchers have observed the use of epistemic devices in different text types. For example, Hyland (1996) found its use in scientific writing; Holmes (1988) and Hyland (1994) observed its use in textbooks; He and Wang (2012) and Mirahayuni (2002) noted its use in academic texts written by non-native speakers; and Tenuta et al. (2015) investigated the use of epistemic modality in English essays written by native Brazilian speakers. Similarly, Moskowich and Crespo (2019), Ngula (2017) and Orta (2010) discovered the use of epistemic modality in research articles; Bista (2009) in political discourse; Molina (2012) in maritime conversations and texts; Nartey and Yankson (2014) in political manifestos; and Siddique et al. (2019) in autobiographies.

The literature has thus shown that the use of epistemic modality markers is critical for writers of academic texts and research articles to enhance their credibility in the context of scholarly communication. Unlike other studies in the literature that focus on linguistic devices such as modal verbs, auxiliary verbs and adverbs, the study specifically selected modal adjectives using a combination of quantitative and qualitative methods of analysis for its investigation. It is important to mention here that the present study only highlights the linguistic manifestations of the idea in research articles published in applied linguistic journals. It is hoped that the results obtained from the study can provide more insight and a comprehensive understanding of how academic writers in the field recognise its value and construct arguments in writing by using epistemic modalities, when appropriate. This will enable them to soften their statements and minimise contradictions or demeaning actions.

\section{Research Method}

\subsection{Data compilation}

Tognini-Bonelli (2001) suggested criteria that must be taken into account when doing a corpus-based analysis. Firstly, the corpus must be composed of authentic samples collected in a realistic context. Secondly, the corpus must be machine-readable so that it can be processed and read by electronic software. Finally, the corpus created must be balanced and representative because "it contains all the types of text, in the correct proportions, that are needed to make the contents of the corpus an accurate reflection of the whole of the language or variety that it samples" (McEnery \& Hardie, 2012, p. 250). 
The corpus for the present study comprises 255 research articles published in two leading journals in the field of EAP and applied linguistics - the Journal of English for Academic Purposes and the International Journal of Applied Linguistics. Their selection was based on the Social Sciences Citation Index ( $\mathrm{SSCl}$ ) journal rankings in terms of impact factors on the Web of Science and their reputation and prestige in the field. The aforementioned research articles were published between 2015 and 2020. Given the fact that the target journals contain not only research articles but also reviews, commentaries and editorials originating from a wide range of researchers and subfields, each of the articles was carefully checked for content, as their genres are different, and only those articles with the document type "research articles" were selected.

All the data were retrieved and downloaded from the university library database. Since the downloaded articles were initially in PDF format, they were converted to plain text format to create the corpus. The articles were then cleaned by excluding the bibliometric information of all articles, including author names, titles, abstracts, references and appendices. After this cleaning process, each article was saved and stored separately by tagging issue and year of publication, sources, file numbers, and word and token types. Thus, the study's corpus comprises 255 research articles or $1,776,772$ words or $2,245,145$ tokens.

\subsection{Research procedures}

A quantitative examination supplemented by a manual contextual analysis was performed for all instances of interactional metadiscourse devices in the corpus in order to identify their discourse functions. To determine a list of adjectives with potential epistemic value that would form the basis for querying the corpus, previous studies were first consulted (Hyland \& Milton, 1997; McEnery \& Kifle, 2002; Rizomilioti, 2006) in which most lexical forms were mentioned to signal epistemic modality. This resulted in 20 forms: apparent, a certain extent, certain, clear, convincing, evident, improbable, inevitable, likely, obvious, possible, probably, speculative, suggestive, sure, true, unclear, unlikely and wellknown. In order to successfully address the research questions, these 20 adjectives were classified into three types - weak, moderate and strong (McEnery \& Kifle, 2002) - according to their degree of epistemic force and probability. The selection of epistemic modality adjectives on the basis of their frequency in academic writing and research articles appears to be a meaningful starting point for discussing the use of a semantic-pragmatic category such as epistemic modality (Vold, 2006).

Before conducting the analysis of epistemic adjectives in the corpus of research articles, the parts of speech identified by Sketch Engine were initially checked (Kilgarriff et al., 2014; Kilgarriff et al. 2004). This commercially available software is used in various fields of linguistics and language studies such as dictionary compilation, phraseology and collocations. After each instance of adjective use was extracted from the corpus, the concordance lines for each occurring adjective were examined in more detail to determine epistemic uses versus non-epistemic uses. This line-by-line examination was crucial because an adjective used in a particular context might serve other pragmatic functions besides encoding epistemic meanings. In many instances, the full text in the allocation of categories was consulted as the linguistic environment in which a pronoun occured, which has been shown to be important for role assignment (Harwood, 2005). After the review and selection of epistemic adjectives and the exclusion of non-epistemic uses, a total of 5,679 out of 3,533 adjectives were epistemically used. 
Throughout the study, extracts from the research articles in the corpus were used to illustrate the emerging arguments. Each article is numbered and allocated a letter based on the journal title, issue and year of publication. The given code is shown in brackets after each excerpt to facilitate the analysis process when referring to the article in the corpus.

\section{Results and Discussion}

\subsection{Use of epistemic adjectives in applied linguistic research articles (RA)}

From the quantitative and qualitative analyses, this section presents the results of the use of epistemic adjectives functioning as an interactional metadiscourse. Table 3 presents the overall distribution of epistemic adjectives together with their normalised frequencies per million tokens in the corpus.

\begin{tabular}{|c|c|c|c|c|c|}
\hline $\begin{array}{c}\text { Epistemic } \\
\text { Adjectives }\end{array}$ & Freq. & $\begin{array}{c}\text { Epistemic occ. f/ } \\
\text { million tokens }\end{array}$ & $\begin{array}{c}\text { Epistemic } \\
\text { Adjectives }\end{array}$ & Freq. & $\begin{array}{c}\text { Epistemic occ. f/ } \\
\text { million tokens }\end{array}$ \\
\hline apparent & 89 & 40.18 & possible & 823 & 371.53 \\
\hline a certain extent & 16 & 7.22 & probably & 17 & 7.67 \\
\hline certain & 565 & 255.06 & speculative & 7 & 3.16 \\
\hline clear & 576 & 260.03 & suggestive & 9 & 4.06 \\
\hline convincing & 41 & 18.51 & sure & 123 & 55.53 \\
\hline evident & 160 & 72.23 & obvious & 78 & 35.21 \\
\hline improbable & 2 & 0.9 & true & 182 & 82.16 \\
\hline inevitable & 22 & 9.93 & unclear & 67 & 30.25 \\
\hline likely & 593 & 267.7 & unlikely & 59 & 26.63 \\
\hline obvious & 78 & 35.21 & well-known & 26 & 11.74 \\
\hline
\end{tabular}

Table 3. Overall frequency of epistemic adjectives in the RA corpus

From the quantitative analysis, it is clear that professional writers preferred to use 'possible' most frequently in their research articles (823 occurrences), followed by 'likely' (593 occurrences), 'clear' (576 occurrences) and 'certain' (565 occurrences). However, some epistemic adjectives occurred with a significantly lower frequency; for example 'probably' (17 occurrences), 'a certain extent' (16 occurrences), and 'suggestive' and 'improbable' (9 and 2 occurrences, respectively) were rarely used by the authors.

To strengthen the quantitative findings of the study, the linguistic occurrences signalling epistemic value were also closely examined, with a special focus on their pragmatic functions serving similar semantic and pragmatic purposes. Corpus examples (1) to (4) illustrate the use of the epistemic adjectives 'possible' and 'likely' in the corpus:

(1) One possible reason for fewer genre differences in Yoon and Polio is that they used a more homogeneous population than was used in Lu's study.

[EWAL 10-2018]

(2) Comparing MAVL with MAWL As is the case with the comparison between Gardner and Davies (2014) AVL and Coxhead's (2000) AWL mentioned above, it is not possible to directly compare the coverage of our lemma-based MAVL with Wang, Liang, and Ge's (2008) word family based MAWL.

[EW 12-2016]

(3) Moreover, the findings suggest that CS between Arabic and Hebrew is likely to be the preferred choice in public discourse in the Mount Carmel area, in fact Hebrew, the EL, is found in the discourse as much as Arabic, even more in some cases.

[EWAL 10-2016] 
(4) Due to these documented benefits of digital storytelling tasks, it is likely that educators at all levels and in most subjects can use digital storytelling in many ways to support students' learning by encouraging them to organize and express their ideas and knowledge in an individual and meaningful way (Robin 2008).

[EWAL 24-2017]

Not surprisingly, 'possible' and 'likely' appear as the two crucial epistemic modality adjectives for applied linguistic writers. These findings suggest their importance as hedging devices used to avoid categorical involvement, commitment and binding of research claims. This supports the findings by Hyland $(2009 ; 2010)$ who claims that "the devices possible and likely, among others, are twice as common in humanities and social science papers than in hard sciences" (p. 13). Hyland discusses that in the softer sciences there is "less control of variables, a greater variety of research outcomes, and fewer clear bases for accepting claims than in the sciences". In the present study, while one can understand the predominance of possible and likely in the fields of humanities and social sciences, this perhaps reflects the challenge and subtle constraints in comparing linguistic and rhetorical features within the large domain of such fields.

The adjective 'clear' is the third most important epistemic modality adjective found in the corpus. In this regard, article writers use the adjective 'clear' epistemically to make strong claims when they are very confident that the available evidence justifies the claims, or when they have supporting evidence for making claims about research findings or discoveries. While Hyland (2009) recognizes clear, alongside others such as evident and obvious, as important adjectives to support research claims, Biber et al. (1999) and Biber (2006) describe their value in academic prose as expressing a self-conscious epistemic stance. The following are examples of epistemic uses of clear in the corpus:

(5) They provide clear examples of how the oral and written language was minimally altered such as by correcting punctuation and incomplete sentences.

[EWAL 10-2018]

(6) As shown in Figure 2a, there is a clear pattern of localisation in the Longman textbooks, visible in their inclusion of more Hong Kong people (e.g., local students and teachers) in their pictures throughout the years (4.7\% to $36.7 \%$ ).

[EWAL 14-2020]

In the field of applied linguistics, the epistemic adjective 'clear' is frequently used to show the article writers' clear preferences. With this epistemic adjective, writers can express the degree of quantification, the standpoint of certainty or uncertainty, and the subjectivity or objectivity of their modalised statements. Occasionally, in some research articles, certainty or uncertainty is not about the facts but about their interpretation.

(7) There is also a tendency to adhere to the formulaic five-paragraph essay structure, with the inclusion of certain elements such as a counter argument merely because the model specifies it, rather than to introduce a relevant argument.

[EW 11-2015]

(8) Awareness of frequency, for example, can help in avoiding common cases of overuse or underuse of certain language forms.

[EWAL 23-2017] 


\subsection{Typical phraseological patterns of core epistemic adjectives}

The use of epistemic adjectives in the corpus of research articles reveals some typical patterns. According to Hunston and Thompson $(2000,2006)$ and Groom (2005), these types of phraseological patterns can contribute to epistemic meaning. In this study, this dimension is achieved through a qualitative concordance analysis of the most frequently used epistemic adjectives in the corpus, namely the adjectives 'possible', 'likely' and 'clear', to see to what extent they are used as a phraseological unit in an environmental context.

\subsubsection{It + Verb + Adjective + that clause}

In the applied linguistic research articles, a close examination of concordance analysis shows that a number of epistemic adjectives, including the most dominant ones (e.g., possible, likely, clear and obvious), enter into the pattern it + verb + adj. + that-clause. In other studies, this phraseological pattern has been shown to be one that writers rely on to emphasise the epistemic validity of an assertion or proposition (e.g. Charles, 2000; Hunston \& Thompson, 2002, 2006; Groom, 2005, Ngula, 2015). The following examples (9) and (10) illustrate this pattern in the research article in applied linguistics with 'possible', which is used by the writers to indicate the writers' stance concerning the given information. This pattern also indicates a lower degree of certainty about the hedged proposition and/or expresses "a little less certainty about the possibility" (Palmer, 2001: 58).

(9) Hence, it is possible that successful cultural adjustment leads to greater access to opportunities for pragmatic practice.

[EWAP 16-2015]

(10) It is possible that the struggling students lack the strategies and resources to scaffold themselves, to gradually close the gap and reach the level of target professional writing.

[EW 34-2016]

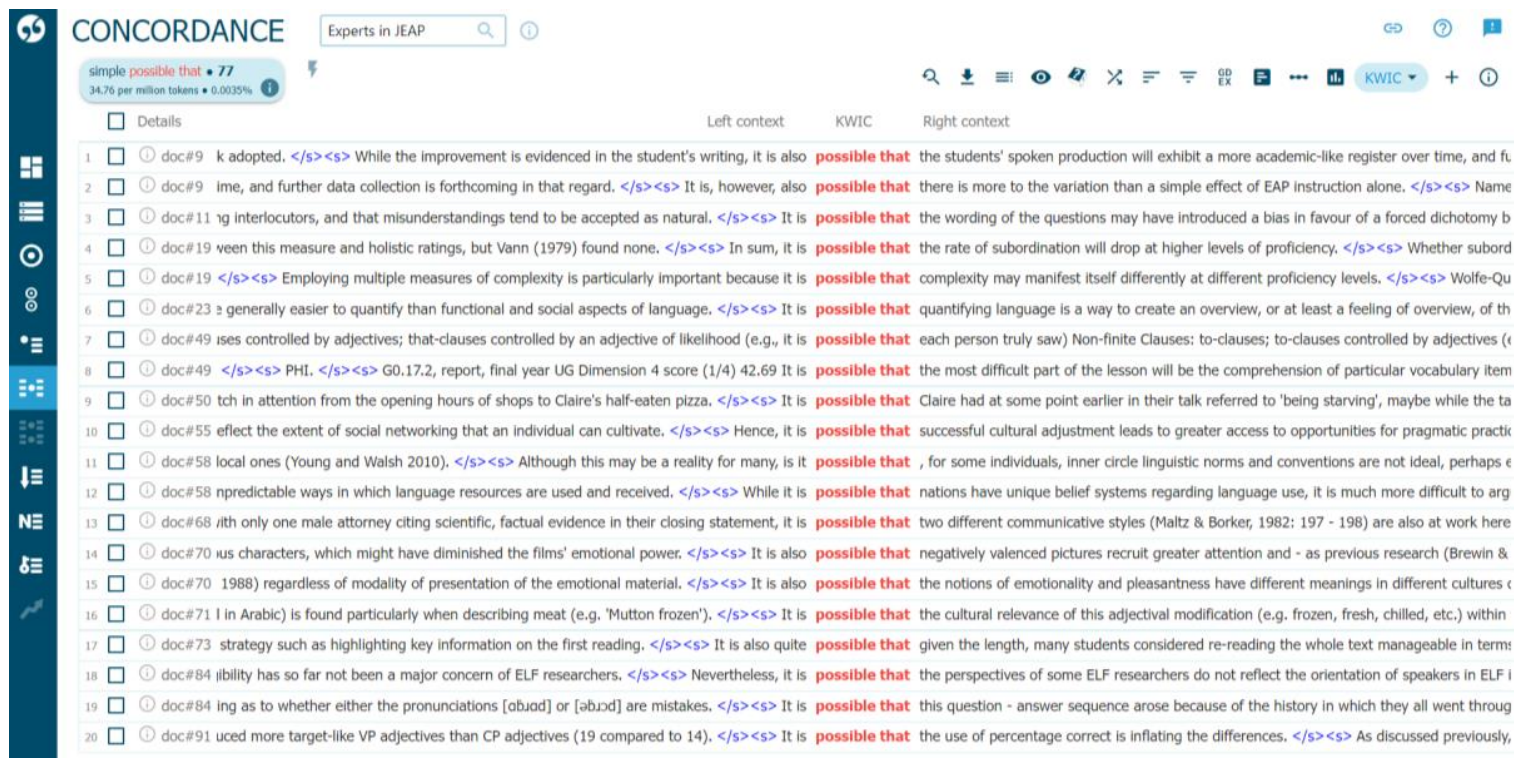

Figure 1. Concordance lines for the it $V$-link possible that-clause pattern in the corpus

The epistemic meaning expressed by 'likely' in the pattern it V-link ADJ that-clause is one of probability, which shows a much stronger epistemic force than epistemic possibility. Examples (11) and (12) illustrate the use of this pattern with 'likely' in the corpus. 
(11) Although most did not provide an explanation for this choice, it is likely that the option did not in fact imply that the respondents did not know what they preferred, but rather their indecision in weighing up the pros and cons of NS and NNS interaction.

[EWAL 11-2017]

(12) For the present study, while the ADAL/HAEP groups were not statistically significantly different, it is likely that members of the two groups were (similarly) more effective in using bottom-up processing when their local comprehension skills for listening were being assessed.

[EW 35-2016]

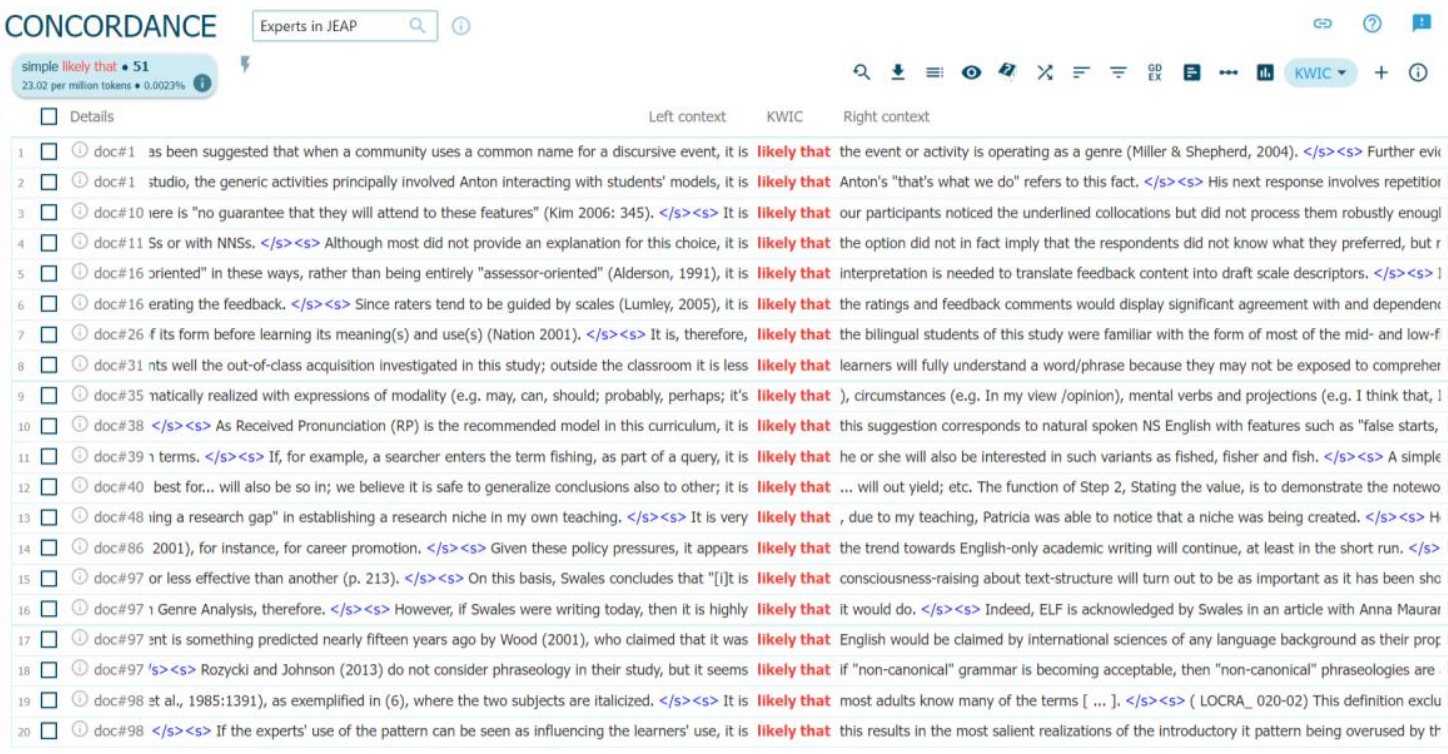

Figure 2. Concordance lines for the it V-link likely that-clause pattern in the corpus

The epistemic meaning expressed by likely in this pattern is one of probability, a much stronger epistemic force than epistemic possibility. However, when the pattern includes 'likely' as an adjective in the sentence, it is less rigid. The reason for this is that the epistemic meaning of probability conveyed is less affected by the that-clause, than in the case of 'possible', so that the epistemic meaning remains intact even without the that-clause following the adjective, as in example (13).

(13) Because of its ubiquity in communication and teaching, it is likely to be instinctive for many lecturers to use humour in a classroom.

[EW 59-2019]

The structural adjustment of the occurrence of 'likely' in (13) could change the epistemic value. A typical case in point involves the negation of likely in the pattern, expressed either as it is not likely that or in the form of a derivational affixation (i.e. 'it is unlikely that'). In this pattern of negation, it is obvious that there is no probability, but the pattern nevertheless encodes an epistemic meaning, one of doubt or improbability, which is weak and far less certain in terms of epistemic strength. In this regard, it essentially performs the function of hedging, as in example (14). 
(14) Although it is not impossible, it is highly unlikely that the participants in the current study had learned the target collocations from sources outside of the classroom during those three weeks.

[EWAL 31-2020]

Instances (15) and (16) illustrate the use of this pattern with 'clear' and 'obvious' in the corpus, which are used to make strong assertions and to make readers see that the proposition and claim being made is obvious and transparent. Figure 3 also shows the concordance lines for the pattern it $V$-link clear that-clause in the research article corpus.

(15) In any case, given the sheer size of the lexicon, including its phrasal dimension, it is clear that the challenge of mastering this cannot be met through explicit teaching or deliberate study alone (Nation 2013: 92).

[EWAL 20-2017]

(16) From my experience with teaching Swiss students who already know Norwegian or Swedish, it is obvious that they have advantages as compared to other students, especially when it comes to understanding texts, but also with regard to grammar or vocabulary learning.

[EWAP 12-2015]

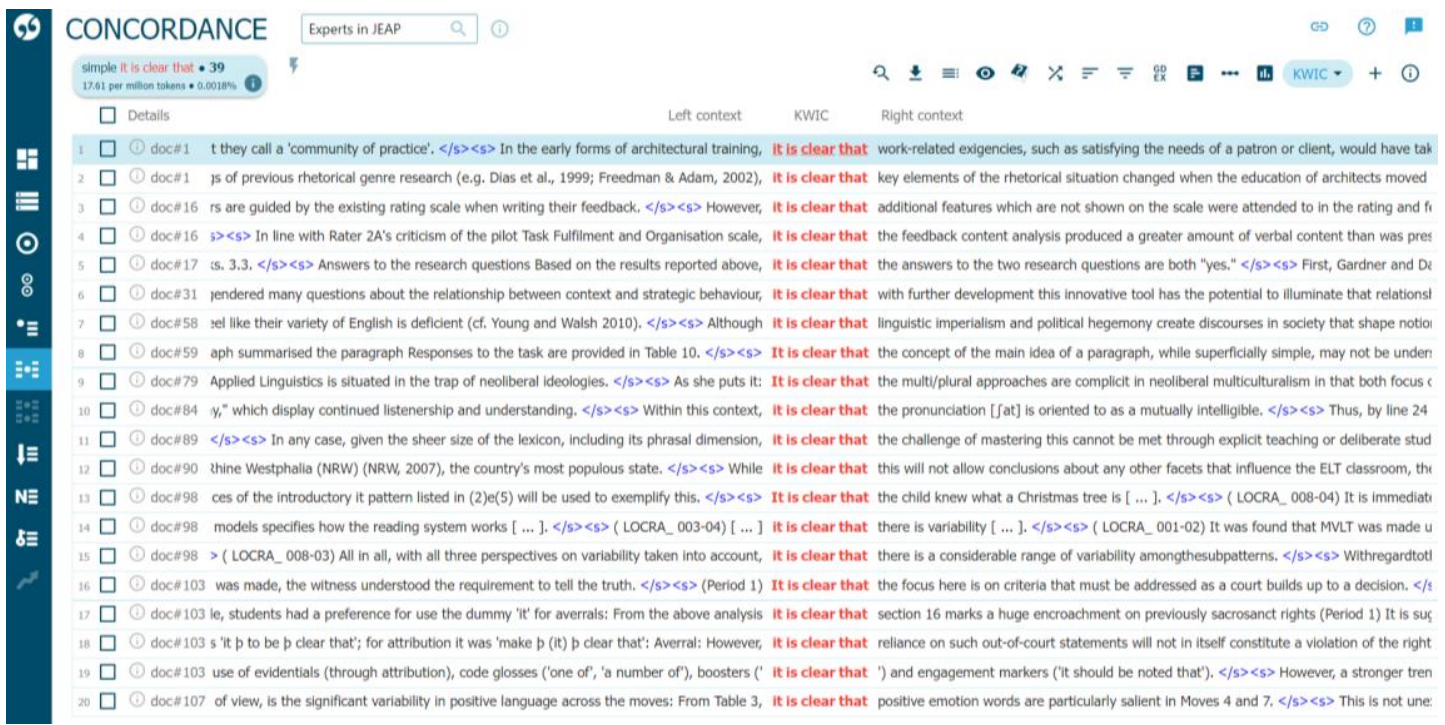

Figure 3. Concordance lines for the it $V$-link clear that-clause pattern in the corpus

As shown earlier, the epistemic forms possible, likely, clear and obvious are rather typical of the collocational pattern it v-link $A D J$ that-clause and it is important to note that the epistemic senses of possibility inherent in possible and likely, respectively are not particularly dependent on these words per se. As Groom (2005) notes, the validity of the epistemic meanings is constrained by the pattern, so that certain syntagmatic changes in this pattern can drastically affect the epistemic meaning. Regarding the specific case of 'possible' for instance, if we were to replace the that-clause following ADJ with a to/for phrase or clause, as in example (17), which expresses a root rather than an epistemic possibility (glossed as something like 'one can expose the beliefs...', which is clearly not epistemic), the epistemic meaning would change to a root-possibility meaning.

(17) Through the detection of grammar and vocabulary items selected by language users, it is possible to expose the beliefs underlying a given piece of discourse.

[EWAL 18-2018] 
(18) As long as the student remembers what he or she has learned, it is possible for him or her to reproduce it; thus, what comes in goes out as long as the student has a good memory.

[EWAL 6-2017]

Therefore, the that-clause in the it $V$-link $A D J$ that-clause pattern is as important as the other parts of the syntagm, in deriving the epistemic meaning expressed by 'possible'. In the research article corpus, this pattern is used by writers as a weakening or mitigating epistemic resource to signal a less confident position in relation to the claim being made.

\subsubsection{Be + ADV + likely + to-infinitive Clause}

Another notable epistemic phraseology in the corpus of research articles concerns the adjective 'likely', which frequently occurs in the sequence be+ADV+ likely + to-infinitive clause. The adverb modifiers that occur in this pattern include less, more and most, which can be considered optional elements. It is interesting to observe how the occurrence of each adverb in this pattern slightly affects the probability sense, which is mainly expressed by likely. As 'less' rhetorically weakens the probability meaning in this pattern, it is further strengthened by the modifiers 'more' and 'most', most being the stronger of the two. Examples (19) to (21) from the corpus illustrate the four observed variants of this pattern:

(19) Thus, by the time the students reach their final test, they are much more likely to produce texts with a high frequency of nominalisations, compared with their production at earlier data points (Fig. 3).

[EW 11-2016]

(20) Thus, for example, EFL learners in Europe are more likely to view British English speech as useful and desirable, whereas EFL learners in Latin America are expected to favour American English speech.

[EWAL 19-2017]

(21) In the workplace, Hilgendorf (2007) identified the areas of politics, law, business, advertisement and academia as those where Germans are most likely to use English in lingua franca settings.

[EWAL 20-2018]

According to Charles (2000) and Groom (2005), the 'that-clause' in the it V-link ADJ thatclause pattern is crucial for validating the epistemic meaning conveyed by the pattern, the 'to-clause' in the be (less/more/most) likely to-clause, as in examples (27) to (30) above, emphasises processes in Halliday's sense (see e.g. Halliday, 1994). In SFL, processes are recognised as 'one of the three core structural elements of experience', actualised by verbs of happening, doing, sensing, saying, being or having (Matthiessen et al, 2010: 164). As Flowerdew (2013) indicates, the group of words encoding a process may be finite or nonfinite. In the phraseological pattern considered here, the verbal elements in the 'to-clause' are all non-finite, as examples (19) to (21) above demonstrate. The importance of the 'toclause' in this pattern is thus mainly seen in its role in introducing new information, which the authors present and explain provisionally, given the epistemic importance of the pattern as a whole, in order to avoid the risk of being rather categorical. The use of more between 'be' and 'likely' in the pattern, as illustrated by the concordance lines, is shown in Figure 4. 


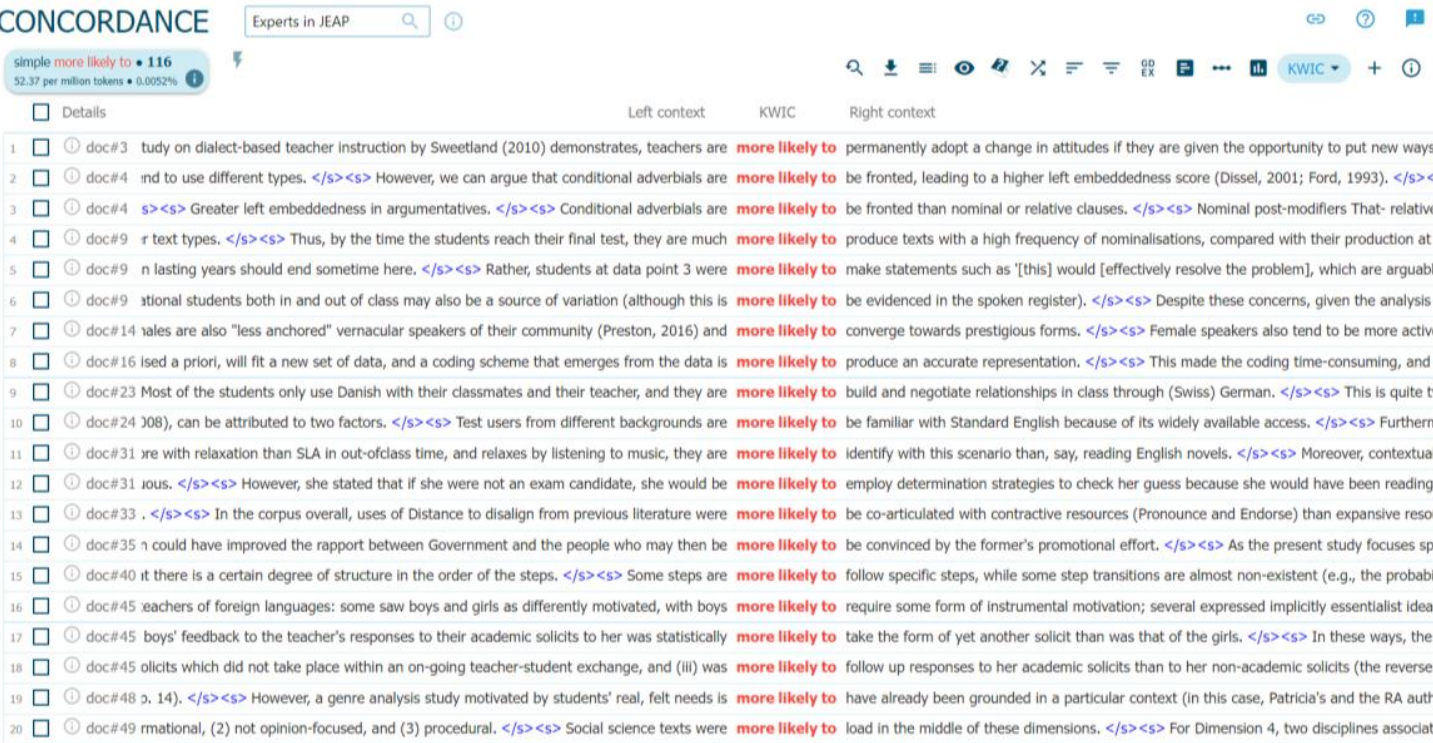

Figure 4. Concordance lines for the Be + more + likely + to-infinitive clause pattern in the corpus

\subsection{Strength of epistemic modality}

This section presents the qualitative results based on the three most frequently used epistemic adjectives found in the analysis: possible, likely and clear. Semantically, each epistemic adjective represents the degrees of strength: strong, medium and weak. Among these adjectives, clear is considered a strong epistemic device; likely (with its intensification modifiers) can generally be classified under the medium level on the continuum of strong, medium and weak; and possible is considered a weak epistemic device. Because of their frequency of occurrence in the corpus, focus was placed on these three linguistic features. While writers have a range of choices for the strong (e.g., clear, obvious, true, well-known) and medium (e.g., likely, apparent, probable) level adjectives, possible and probable are the main productive weak-level epistemic adjectives in the list of epistemic items examined in this study. Thus, focusing on clear, likely and possible provides a fair assessment of writers' preferences for epistemic adjectives expressing strong, medium and weak levels of epistemic strength. Examples (22) to (24) are intended to illustrate how these epistemic adjectives encode levels of epistemic strength in context.

(22) Indeed, from our preliminary analysis, it was clear that some writers at certain score levels used the source texts more than the others.

[EW 36-2016]

(23) Participants were exposed to the Polish translations of these items on Test 1 and therefore it was not possible to measure their knowledge of meaning recall as they were likely to remember the correct answers they had seen.

[EWAL 11-2016]

(24) At the study level, it is possible that only those students who have been successfully socialized into the English academic discourse community participated in the survey and focus groups.

[EW 52-2020]

In particular, studies on epistemic modality (e.g. Biber, 2006; Ağçam, 2014) have found it more convenient to classify the strength of epistemic adjectives into 1) certainty adjectives (e.g. certain, obvious, clear) and 2) likelihood adjectives (e.g. probable, likely, possible). The 
threefold grouping of strong, medium and weak degrees of likelihood was chosen to provide a more accurate and effective classification of epistemic adjectives. On the one hand, the term 'certainty' partly implies the absence of an epistemic modality. On the other hand, the term 'likelihood' itself might be sufficient to classify epistemic adjectives, including so-called 'certainty', using a continuum of strong, medium and weak degrees, so that forms like certain, probable and possible can represent these three degrees of 'likelihood' more usefully.

The aim of this corpus analysis, which focused on adjectives of epistemic modality in applied linguistics research articles, was to find out to what extent their rhetorical practises deviate adjectivally from mainstream international conventions on epistemic modality in research articles published in distinguished journals. The study was primarily based on SketchEngine (Kilgarriff, 2014; Kilgarriff et al., 2004). The frequency of epistemic adjectives used in the corpus was examined, leading to interesting qualitative assessments about the use of epistemic adjectives in the selected data, as the study included both quantitative and qualitative aspects. A further examination of the concordance results could help to enrich the qualitative aspects of the study, especially with regard to the identification and interpretation of phraseological patterns or patterns of co-occurrence in some of the main epistemic resources.

Regarding the linguistic forms that encode epistemic modality, this study revealed that the distributional pattern of epistemic modality adjectives, among other linguistic features such as modal verbs, adverbs or nouns, is essential for academic writers for the publication of research articles in various international journals. Professional writers use a wide range of epistemic lexical vocabulary to support their claims and propositions. Moreover, the analysis of this study supports the idea that article writers deploy a rhetorical awareness with an extensive epistemic vocabulary at their disposal. This is evident not only in the depth with which they use these resources to support their claims but also in the way certain epistemic forms and patterns of co-occurrence are used to achieve certain epistemic rhetorical effects.

The findings of this study offer insight into the topic of academic and scholarly writing rhetoric, especially for aspiring academic writers and graduate students who wish to publish their research findings in academic journals. According to the findings, it would be beneficial for writers to make significant use of the epistemic adjectives 'possible', 'likely' and 'clear' in the co-occurrence pattern of it $V$-link $A D J$ that-clause to conform to international rhetorical standards. Furthermore, they should consider the employment of mitigating epistemic adjective forms such as 'possible' and 'probable', even if they occur in the co-occurrence pattern of be + ADV + likely + to- clause.

The present study suggests important pedagogical implications rooted in direct and explicit teaching and learning of epistemic devices and metadiscourse, which need to be introduced and encouraged. Flowerdew (1999; 2008), Martinéz (2011) and Swales (2004) have suggested that the language and rhetoric of an academic paper should be taught to all those who wish to publish in English-language international journals. This may be a more pressing need for non-native speakers of English in less privileged academic contexts, especially in the EFL context. In this regard, it would be useful for teachers to engage experienced EAP specialists to provide regular EAP courses and workshops on academic writing for students, especially at postgraduate level. Such courses and workshops would aim to teach participants the rhetorical and lexico-grammatical conventions of academic writing. As Molino (2018) suggests, activities based on authentic experiences that encourage reflection on appropriate use in a particular setting can contribute to the use of such 
linguistic devices for specific purposes. The findings of the present study may be employed for these instructional purposes. In this way, novice and graduate writers can become aware of the particular practises and expectations of the academic community to which they will be contributing. This is in line with Hyland (2000) who suggested that "a clear awareness of the pragmatic impact of hedges and boosters and an ability to recognise them in texts is crucial to the acquisition of a rhetorical competence in any discipline" (p. 193). Such competence may also be achieved by providing authentic material on metadiscourses (e.g. Alotaibi, 2018; Bogdanović \& Mirović, 2018), so that writers can acquire certain linguistic patterns and functions to integrate them into the rhetorical organisation of their own texts.

There are crucial aspects of this study that could not be addressed due to inevitable limitations, such as time and size constraints in addition to the scope of the research imposed by the corpus studied. The pragmatic nuances characterising each of the epistemic adjectives studied were difficult, if not impossible, to explore in detail, as the research focused solely upon a rather large number of epistemic adjectives. As a result, only a limited number of epistemic devices could be studied extensively from a semantic and pragmatic perspective. These can potentially provide new insights into how they are used in environmental contexts to support rhetorical practises. Other linguistic features of academic writing, such as adverbs, modal auxiliary verbs, nouns, authorial presence, collocational patterns and discourse structure, should be of interest in terms of epistemic values and contribute to our overall understanding of scholarly writing practises. Since all disciplines differ in their nature, goals and genres, further research comparing different domains and aspects is needed to discover further epistemic modalities across different disciplines and possibly determine domain-specific patterns.

\section{Conclusion}

This study investigated how adjectives encode epistemic modality and what remarkable phraseological or collocational patterns these adjectives of epistemic value exhibit. The corpus analysis indicates that the use of epistemic adjectives in international research articles in the field of applied linguistics is rather extensive. The results demonstrate the professional writers' keen awareness of epistemic adjectives in their academic texts, as evidenced by the depth and breadth of their use. In examining the phraseology of epistemic adjectives, two key structural patterns frequently associated with the prominent epistemic adjectives, the it $v$-link $A D J$ that-clause pattern and the be+ ADV (less/more/most) likely + toinfinitive-clause pattern, were explored. Both proved to be useful patterns that writers of applied linguistic research articles frequently implement to convey different degrees of epistemic modality. Upon closer examination of these patterns in research articles, several qualitative and frequent differences were identified, especially in relation to the pattern of it v-link ADJ that-clause. The epistemic adjectives clear (strong), likely (medium) and possible (weak) were used to assess the pattern of epistemic strength. This study indicates that the epistemic adjectives likely and possible (which reduce the strength of a claim) were shown to be valued higher than the epistemic adjective clear (which increases the strength). The study results shed light on how professional article writers use lexico-grammatical features, especially epistemic adjectives, to increase the persuasiveness of their arguments and the text as a whole. In addition, aspiring academic writers and graduate students can make full use of the knowledge presented to submit their texts for publication. 


\section{Acknowledgements}

This work was supported by the Bachelor of Arts in English (Special Program), Department of English, Faculty of Liberal Arts and Science, Kasetsart University (Grant number 1/2562). I would like to thank Mr. Daniel Lebedies for his constructive comments and assistance in the preparation stage of this paper.

\section{References}

Abdi, R. (2009). Projecting cultural identity through metadiscourse marking: A comparison of Persian and English research articles. Journal of English Language Teaching and Learning, 52(212), 1-15.

Abdi, R. (2011). Metadiscourse strategies in research articles: A study of the differences across subsections. The Journal of Teaching Language Skills, 3(1), 1-16.

Ağçam, R. (2014). A corpus-based study on epistemic adjectives in academic English. American Journal of Educational Research, 2(12), 1230-1236.

Alotaibi, H. (2018). Metadiscourse in dissertation acknowledgments: Exploration of gender differences in EFL texts. Educational Sciences: Theory \& Practice, 18, 899-916. http://doi.org/10.12738/estp.2018.4.0247

Al-Shunnag, M. A. (2014). Stance in political discourse: Arabic translations of American newspaper opinion articles on the 'Arab Spring'. Unpublished Ph.D dissertation, The University of Salford.

Ardizzone, P., \& Pennisi, G. A. (2012). Epistemic modality variation in community law journals. In S. M. Maci \& M. Sala (Eds.), Genre variation in academic communication: Emerging disciplinary trends (pp. 153-174). Bergamo: CELSB.

Aull, L. L., \& Lancaster, Z. (2014). Linguistic markers of stance in early and advanced academic writing: A corpus-based comparison. Written Communication, 31, 151-183. https://doi.org/10.1177/0741088314527055

Babaii, E., Atai, M. R., \& Mohammadi, V. (2015). Stance in English research articles: Two disciplines of the same science. TELL, 9(1), 1-27.

Biber, D., Johansson, S., Leech, G., Conrad, S., \& Finegan, E. (1999). Longman grammar of spoken and written English. Harlow: Longman.

Biber, D. (2004). Historical patterns for the grammatical marking of stance: A cross-register comparison. Journal of Historical Pragmatics, 5, 107-135. https://doi.org/10.1075/jhp.5.1.06bib

Biber, D. (2006). Stance in spoken and written university registers. Journal of English for Academic Purposes, 5, 97-116. https://doi.org/10.1016/j.jeap.2006.05.001

Bista, K. (2009). On 'yes, we can': Linguistic power and possibility. Journal of English for Specific Purpose, 3(24), 34- 50.

Blagojevic, S. (2004). Metadiscourse in academic prose: A contrastive study of academic articles written in English by English and Norwegian speakers. Studies About Linguistics, 5, 1-7.

Blagojevic, S. (2004). Metadiscourse in academic prose: A contrastive study of academic articles written in English by English and Norwegian speakers. Studies About Linguistics, 5, 1-7.

Bogdanović, V., \& Mirović, I. (2018). Young researchers writing in ESL and the use of metadiscourse: Learning the ropes. Educational Sciences: Theory \& Practice, 18, 813830. http://doi.org/10.12738/estp.2018.4.0031 
Brogaard, B., \& Gatzia, D. (2017). Introduction: Epistemic modals, Topoi, 36(1), 127-130. http://doi.org/10.1007/s11245-016-9374-3

Çapar, M. (2014). A study on metadiscourse markers in research articles. Unpublished PhD thesis, Anadolu University.

Charles, M. (2000). The role of an introductory it pattern in constructing an appropriate academic persona. In P. Thompson (Ed.), Patterns and perspectives: Insights into EAP writing practice (pp. 45-59). CALS: The University of Reading.

Chen, H. I. (2010). Contrastive learner corpus analysis of epistemic modality and interlanguage pragmatic competence in L2 writing. Arizona working papers in SLA \& teaching, 17, 27-51.

Chovanec, J. (2012). Written academic discourse in English: From local traditions to global outreach. Brno Studies in English, 38(2), 5-16. http://doi.org.10.5817/BSE2012-2-1

Conrad, S., \& Biber, D. (2000). Adverbial marking of stance in speech and writing. In S. Hunston \& G. Thompson (Eds.), Evaluation in text: Authorial stance and the construction of discourse (pp. 56-73). New York: Oxford University Press.

Crismore, A., \& Farnsworth, R. (1990). Metadiscourse in popular and professional science discourse. In W. Nash (Ed.), The Writing Scholar: Studies in the Language and Conventions of Academic Discourse (pp. 45-68). Newbury Park, CA: Sage Publication.

Del Saz-Rubio, M. (2011). A pragmatic approach to the macro-structure and metadiscoursal features of research article introductions in the field of Agricultural Sciences. English for Specific Purposes, 30(4), 258-271. https://doi.org/10.1016/j.esp.2011.03.002

Fintel, K. von and Gillies, A. S. (2007). An opinionated guide to epistemic modality. In T. S. Gendler \& J. Hawthorne (Eds.), Oxford Studies in epistemology, 2 (pp. 32-62). Oxford: Oxford University Press.

Flowerdew, J., \& Li, Y. (2009). English or Chinese? The trade-off between local and international publication among Chinese academics in the humanities and social sciences. Journal of Second Language Writing, 18, 1-16. https://doi.org/10.1016/j.jslw.2008.09.005

Flowerdew, J. (2013). Discourse in English language education. New York: Routledge.

Flowerdew, L. (1998). Corpus linguistic techniques applied to textlinguistics. System, 26, 541-552.

Flowerdew, J. (1999). Writing for scholarly publication in English: the case of Hong Kong. Journal of Second Language Writing, 8, 123-145. https://doi.org/10.1016/S10603743(99)80125-8

Flowerdew, J. (2008). Scholarly writers who use English as an additional language: What can Goffman's "Stigma" tell us? Journal of English for Academic Purposes, 7, 77-86. https://doi.org/10.1016/j.jeap.2008.03.002

Ghahremani Mina, K., \& Biria, R. (2017). Exploring interactive and interactional metadiscourse markers in discussion sections of social and medical science articles. International Journal of Research in English Education, 2(4), 11-29.

Giannoni, D. (2008). Medical writing at the periphery: The case of Italian journal editorials. Journal of English for Academic Purposes, 7, 97-107. https://doi.org/10.1016/j.jeap.2008.03.003

Gillaerts, P., \& Van de Velde, F. (2010). Interactional metadiscourse in research article abstracts. Journal of English for Academic Purposes, 9(2), 128-139. https://doi.org/10.1016/j.jeap.2010.02.004 
Groom, N. (2005). Pattern and meaning across genres and disciplines: An exploratory study. Journal of English for Academic Purposes, 4(3). 257-277. https://doi.org/10.1016/j.jeap.2005.03.002

Halliday, M. A. K. (1994). An introduction to functional grammar. London: Edward Arnold.

Harwood, N. (2005). 'Nowhere has anyone attempted... In this article I aim to do just that': A corpus-based study of self-promotional I and we in academic writing across four disciplines. Journal of Pragmatics, 37, 1207-1231. https://doi.org/10.1016/j.pragma.2005.01.012

Ho, V., \& Li, C. (2018). The use of metadiscourse and persuasion: An analysis of first year university students' timed argumentative essays. Journal of English for Academic Purposes, 33, 53-68. https://doi.org/10.1016/j.jeap.2018.02.001

Holmes, J. (1988). Doubt and certainty in ESL textbooks. Applied Linguistics, 9(1), 21 -44.

Hong, H. Q., \& Cao, F. (2014). Interactional metadiscourse in young EFL learner writing A corpus-based study. International Journal of corpus linguistics, 19(2), 201-224. https://doi.org/10.1075/ijcl.19.2.03hon

Hoye, L. (1997). Adverbs and modality in English. London and New York: Longman.

Huddleston, R., \& Pullum, G. K. (2002). The Cambridge grammar of the English language. Cambridge: Cambridge University Press.

Hunston, S., \& Thompson, G. (2000). Evaluation: An introduction. In S. Hunston \& G. Thompson (Eds.), Evaluation in text: Authorial stance and the construction of discourse (pp. 1-27). Oxford: Oxford University Press.

Hunston, S., \& Thompson, G. (2006). Evaluation in text. In K. Brown (Ed.), The Encyclopedia of Language and Linguistics Volume 4 (pp. 305-312). Oxford: Elsevier.

Hunston, S. (1994). Evaluation and organisation in a sample of written academic discourse. In M. Coulthard (Ed.), Advances in written text analysis (pp. 191-218). London: Routledge.

Hyland, K., \& Milton, J. (1997). Qualification and certainty in L1 and L2 students' writing. Journal of Second Language Writing, 6(2), 183-205. https://doi.org/10.1016/s10603743(97)90033-3

Hyland, K., \& Tse, P. (2004). Metadiscourse in academic writing: A reappraisal. Applied Linguistics, 25(2), 156-177. https://doi.org/10.1093/applin/25.2.156

Hyland, K. (1994). Hedging in academic writing and EAP textbooks. English for Specific Purposes, 13(3), 239-256. https://doi.org/10.1016/0889-4906(94)90004-3

Hyland, K. (1996). Writing without conviction? Hedging in science research articles. Applied Linguistics, 17(4), 433-454. https://doi.org/10.1093/applin/17.4.433

Hyland, K. (2003). Second language writing. Cambridge: Cambridge University Press.

Hyland, K. (2004). Disciplinary interactions: Metadiscourse in L2 postgraduate writing. Journal of Second Language Writing, 13, 133-151. https://doi.org/10.1016/j.jslw.2004.02.001

Hyland, K. (2005). Metadiscourse: Exploring Interaction in Writing. London: Continuum.

Hyland, K. (2000). Hedges, boosters and lexical invisibility: Noticing modifiers in academic texts. Language Awareness, 9(4), 179-197. https://doi.org/10.1080/09658410008667145 
Hyland, K. (2007). English for professional academic purposes: writing for scholarly publication. In D. Belcher (Ed.), Teaching language purposefully: English for specific purposes in theory and practice (pp. 1-27). New York: Cambridge University Press.

Hyland, K. (2009). Academic discourse. London: Continuum.

Hyland, K. (2010). Constructing proximity: Relating to readers in popular and professional science. Journal of English for Academic Purposes, 9, 116-127. https://doi.org/10.1016/j.jeap.2010.02.003

Hyland, K. (2012). English for academic purposes and discourse analysis. In: J. P. Gee \& M. Handford (Eds.), The Routledge Handbook of Discourse Analysis (pp. 412-423). London: Routledge.

Hyland, K. (2013). Metadiscourse. In K. Hyland (Ed.), Discourse studies reader: Essential excerpts (pp. 65-88). London: Bloomsbury.

Jalilifar, A., Hayati, S., \& Don, A. (2018). Investigating metadiscourse markers in book reviews and blurbs: A study of interested and disinterested genres. Study About Languages, 33, 90-107.

Kanoksilapatham, B. (2015). Distinguishing textual features characterizing structural variation in research articles across three engineering sub-discipline corpora. English for Specific Purposes, 37, 74-86. https://doi.org/10.1016/j.esp.2014.06.008

Kilgarriff, A., Rychlý, P., Smrz, P., \& Tugwell, D. (2004). The Sketch Engine. In Proc Eleventh EURALEX International Congress. Lorient, France.

Kilgarriff, A., Baisa, V., Bušta, J., Jakubíček, M., Kovář, V., Michelfeit, J., Rychlý, P., \& Suchomel, V. (2014). The Sketch Engine: Ten years on. Lexicography, 1, 7-36. http://dx.doi.org/10.1007/s40607-014-0009-9

Kranich, S., \& Gast, V. (2012). Explicitness of epistemic modal marking: Recent changes in British and American English Svenja. Paper presented at MIMS (Multilingual Individuals and Multilingual Societies). Hamburg: Jena.

Lee, J., \& Deakin, L. (2016). Interactions in L1 and L2 undergraduate student writing: Interactional metadiscourse in successful and less-successful argumentative essays. Journal of Second Language Writing, 33, 21-34.

Letsoela, P. M. (2013). Interacting with readers: Metadiscourse features in National University of Lesotho undergraduate students' academic writing. International Journal of Linguistics, 5(6), 138. https://doi.org/10.5296/ijl.v5i6.4012

Lin, L., \& Evans, S. (2012). Structural patterns in empirical research articles: A crossdisciplinary study. English for Specific Purposes, 31(3), 150-160. https://doi.org/10.1016/j.esp.2011.10.002

Loi, C. K., \& Lim, J. M.-H. (2013). Metadiscourse in English and Chinese research article introduction. Discourse Studies, 15, 129-146. https://doi.org/10.1177/1461445612471476

Martin, J. R., \& White, P. R. R. (2005). The language of evaluation: Appraisal in English. Palgrave Macmillan.

Martin, J. R. (2000). Beyond exchange: Appraisal systems in English. In S. Hunston \& G. Thompson (Eds.), Evaluation in text: Authorial stance and the construction of discourse (pp. 142-175). Oxford: Oxford University Press.

Martinéz, I. A. (2005). Native and non-native writers' use of first person pronouns in the different sections of biology research articles in English. Journal of Second Language Writing, 14, 174-190. 
Matthiessen, C. M. I. M., Teruya, K., \& Lam, M. (2010). Key Terms in systemic functional linguistics. London: Continuum.

McEnery, T., \& Hardie, A. (2012). Corpus linguistics: Method, theory and practice. Cambridge: Cambridge University Press.

McEnery, T., \& Kifle, N. A. (2002). Epistemic modality in argumentative essays of secondlanguage

writers. In J. Flowerdew (Ed.), Academic Discourse (pp. 182-195). London: Pearson Education Limited.

Molino, A. (2018). "What I'm speaking is almost English...": A corpus-based study of metadiscourse in English-medium lectures at an Italian university. Educational Sciences: Theory \& Practice, 18, 935-956. http://doi.org/10.12738/estp.2018.4.0330

Moskowich, I., \& Crespo, B. (2019). Arguments that could possibly be urged: Modal verbs and tentativeness in the Coruña corpus. Languages, 4(57), 1-12.

Mu, C., Zhang, L., Ehrich, J., \& Hong, H. (2015). The use of metadiscourse for knowledge construction in Chinese and English research articles. Journal of English for Academic Purposes, 20, 135-148.

Nartey, M., \& Yankson, F. E. (2014). A semantic investigation into the use of modal auxiliary verbs in the manifesto of a Ghanaian political party. International Journal of Humanities and Social Science, 4(3), 21-304.

Ngula, R. S. (2015). Epistemic modality in social science research articles written by Ghanaian authors: A corpus-based study of disciplinary and native vs. non-native variations. Unpublished PhD thesis, Lancaster University.

Ngula, R. S. (2017). Epistemic modal verbs in research articles written by Ghanaian and international scholars: A corpus-based study of three disciplines. Brno Studies in English, 43(2), 5-27. http://doi.org.10.5817/BSE2017-2-1

Orta, I. V. (2010). A contrastive analysis of the use of modal verbs in the expression of epistemic stance in business management research articles in English and Spainish. Ibérica, 19, 77-96.

Özdemir, N. O., \& Longo, B. (2014). Metadiscourse use in thesis abstracts: A cross-cultural study. Procedia - Social and Behavioral Sciences, 141, 59-63. http://doi.org.10.1016/j.sbspro.2014.05.011

Palmer, F. R. (2001). Mood and modality. Cambridge: Cambridge University Press.

Rizomilioti, V. (2006). Exploring epistemic modality in academic discourse using corpora. Information Technology in Languages for Specific Purposes, 73, 53-71.

Salager-Meyer, F., Alcaraz Ariza, M. A., \& Zambrano, N. (2003). The scimitar, the dagger and the glove: intercultural differences in the rhetoric of criticism in Spanish, French and English medical discourse (1930-1995). English for Specific Purposes, 22, 223-247.

Salager-Meyer, F. (2008). Scientific publishing in developing countries: Challenges for the future. Journal of English for Academic Purposes, 7, 121-132. https://doi.org/10.1016/j.jeap.2008.03.009

Siddique, A. R., Shah, S. K., \& Ahmad, M. (2019). Modality in an autobiography 'If I am assassinated' by Zulfiqar Ali Bhutto in English and its Urdu translation. Revista Dilemas Contemporáneos: Educación, Política y Valores, 6, 1-36.

Swales, J. (2004). Research genres. Cambridge: Cambridge University Press.

Tenuta, A. M., Oliveira, A. L. A., \& Orfanó, B. M. (2015). How Brazilian learners express modality through verbs and adverbs in their writing: $A$ corpus-based study on $n-$ grams. DELTA, 31(2), 333-357. 
Thompson, G. (2001). Interaction in academic writing: learning to argue with the reader. Applied Linguistics, 22(1), 58-78. https://doi.org/10.1093/applin/22.1.58

Tognini-Bonelli, E. (2001). Corpus linguistics at work. Amsterdam: John Benjamins.

Vande Kopple, W. J. (2012). The importance of studying metadiscourse. Applied Research on English Language, 1(2), 37-44.

Vandenhoek, T. (2018). Epistemic markers in NS and NNS academic writing. Journal of Academic Writing, 8(1), 72-91. http://doi.org:10.18552/joaw.v8i1.359

Varttala, T. (2003). Hedging in scientific research articles: A cross-disciplinary study. In: G. Cortese \& P. Riley (Eds.) Domain-specific English: Textual practices across communities and classrooms (pp. 141-174). New York: Peter Lang.

Vold, E. T. (2006). Epistemic modality markers in research articles: A cross-linguistic and cross-disciplinary study. International Journal of Applied Linguistics, 16(1), 61-87. https://doi.org/10.1111/j.1473-4192.2006.00106.x 